\title{
TRANSPORTE DE COMPOSTOS NITROGENADOS EM SOJA CULTIVADA COM DIFERENTES FONTES DE NITROGÊNIO (')
}

\author{
HAIKO ENOK SAWAZAKI (2), LADASLAV SODEK (3) \\ Q JOĀO PAULO FEIJĀO TEIXEIRA $(2,4)$
}

\begin{abstract}
RESUMO
Plantas de soja inoculadas com Rhizobium japonicum foram cultivadas em vermiculita com solução nutritiva sem nitrogênio, em casa de vegetação, no Centro Experimental de Campinas, do Instituto Agronômico. Foi estudado o efeito quanto aos niveis de urédeos (alantoina e ácido alantóico), aminoácidos (total e qualitativo por analisador de aminoácidos), $\mathrm{NO}_{3}^{-}$ e $\mathrm{NH}_{4}^{+}$, encontrados na seiva do xilema. Para esse fim, as plantas (noduladas) foram tratadas durante sete dias com soluçōes nutritivas contendo os ions $\mathrm{NO}_{3}^{-}(15 \mathrm{mM})$ ou $\mathrm{NH}_{4}^{+}(10 \mathrm{mM})$ aplicadas próximo à época de floração, ou sem nitrogênio (controle). O ácido alantóico predominou em relação à alantoína, e essa proporção tendeu a aumentar com a exposição da planta a $\mathrm{N}$-mineral. $\mathrm{O}$ transporte de nitrogênio total pelo xilema foi maior para o processo de fixaçāo de $\mathrm{N}_{2}$, decrescendo para o de absorçāo de $\mathrm{NH}_{4}^{+}$e para o de absorção de $\mathrm{NO}_{3}^{-}$, sugerindo que o transporte de nitrogênio tenha dependido da interação entre presença de $\mathrm{N}$-mineral no solo e disponibilidade de energia. A fixação de $N_{2}$, processo mais dispendioso de energia, possibilita maior produção de ureídeos, que exportam mais nitrogênio que os aminoácidos. A asparagina foi o aminoácido encontrado em maior quantidade no
\end{abstract}

(1) Recebido para publicaçāo em 14 de novembro de 1986.

(2) Seção de Fitoquímica, Instituto Agronômico (IAC). Caixa Postal 28. 13001 Campinas (SP).

$\left({ }^{3}\right)$ Departamento de Fisiologia Vegetal, Instituto de Biologia, Universidade de Campinas.

$\left({ }^{4}\right)$ Com bolsa de pesquisa do CNPq. 
xilema, independente do tratamento. $\mathrm{O}$ tratamento $\mathrm{NH}_{4}^{+}$não alterou o teor de $\mathrm{N}-\mathrm{NH}_{4}^{+}$, mas aumentou o nivel de glutamina e asparagina em comparaçāo com o tratamento $\mathrm{NO}_{3}^{-}$, que, por sua vez, aumentou o teor de ácido aspártico e o de $\mathrm{N}-\mathrm{NO}_{3}^{-}$. Esses resultados sugerem que a diferenciação na formação de aminoácidos decorreu dos processos especfficos de absorçāo de nitrogênio.

Termos de indexação: soja, aminoácidos, urefdeos, fixação simbiótica, nutriçăo nitrogenada.

\section{INTRODUÇÃO}

A fixação de nitrogênio é reconhecida como um importante processo de suprimento de nitrogênio às leguminosas. A presença de $N$ no solo afeta o processo de nodulação (COTTINGHAM \& JONES, 1980; WONG \& STENBERG, 1980; HERRIDGE, 1982a, b) e fixação de $N_{2}$ (NOEL et al., 1982, ZENGBÉ et al., 1984) de leguminosas em simbiose com bactérias. É importante melhor compreensão desse fenômeno para fornecer subsidios para a pesquisa visando identificar as causas da inibição. Esta ocasiona, além da necessidade do suprimento de $\mathrm{N}$-mineral ao solo, o gasto de $\mathrm{N}$-residual que poderia ser utilizado por cultura subseqüente.

A menor eficiência de assimilação de nitrogênio na forma de $\mathrm{N}_{2}$ fixado em relação à de $\mathrm{NO}_{3}^{-}$reduzido foi atribuída à maior parte de $\mathrm{C}$ como $\mathrm{CO}_{2}$ na respiração, além de energia para o funcionamento nodular, por ATKINS et al. (1980), ou à maior perda da fotossíntese líquida diária por FINKE et al. (1982), sugerindo o maior requerimento de energia por planta nodulada dependente de $\mathrm{N}_{2}$ de fixação.

Por outro lado, MARCUS-WYNER \& RAINS (1983) sugeriram que a menor absorção de $\mathrm{NH}_{4}^{+}$em plantas noduladas em relação às não-noduladas decorreu do decréscimo na massa das raízes das primeiras.

Leguminosas como a soja possuem processos assimilatórios bem definidos na raiz: a redução e assimilação do nitrato e a fixação simbiótica do nitrogênio atmosférico (nodular). No caso da fixação de $\mathrm{N}_{2}$, os ureídeos são produtos quase que exclusivos do processo (FUHWAPA et at.,- 1977, MATSUMOTO et at., 1977, OHYAMA \& KUMAZAWA, 1979), embora aiguns autores sugiram que decorram também do catabolismo dos ácidos nucléicos (SCHUBERT, 1981) ou do N-amônio assimilado pela planta (HERRIDGE, 1982b).

Os aminoácidos, por sua vez, além de serem produtos da redução e assimilação do nitrato (HAYNES \& GOH, 1978) são também oriundos da fixação de $\mathrm{N}_{2}$ (OHYAMA \& KUMAZAWA, 1979). 
O fluxo de translocação pelos vasos do xilema é reconhecido como o principal meio de transporte do nitrogênio da raiz para a parte aérea (BOLLARD, 1960). Por exame da seiva, pode-se obter informaçōes qualitativas e quantitativas acerca da atividade de assimilação da raiz pelo tipo de composto nitrogenado enviado à parte aérea.

O objetivo deste trabalho, portanto, foi investigar a influência de fontes nitrogenadas $\left(\mathrm{NO}_{3}^{-}\right.$e $\left.\quad \mathrm{NH}_{4}^{+}\right)$sobre a composição da seiva do xilema, visando à melhor compreensão do mecanismo de assimilação e transporte de nitrogênio pela soja.

\section{MATERIAL E MÉTODOS}

Plantas de soja (duas por vaso) foram cultivadas em vermiculita em casa de vegetação. No estádio de folha primária (duas semanas pós-plantio), foram inoculadas com a estirpe eficiente SMS 65 de Rhizobium japonicum e irrigadas duas vezes por semana com solução nutritiva $(250 \mathrm{ml})$ de Hoagland sem nitrogênio e com água quando necessário. De acordo com o tratamento, foram empregadas as seguintes soluçōes: sem nitrogênio $(-\mathrm{N})$, com nitrato $\left(\mathrm{NO}_{3}^{-}\right)$e com amônio $\left(\mathrm{NH}_{4}^{+}\right)$, descritas abaixo.

1) Soluçōes-estoque para macronutrientes utilizadas na proporção de $1 \mathrm{ml} /$ litro de solução nutritiva:

a) Solução $(-\mathrm{N})=\mathrm{KH}_{2} \mathrm{PO}_{4} 1 \mathrm{M} ; \mathrm{K}_{2} \mathrm{SO}_{4} \cdot 7 \mathrm{H}_{2} \mathrm{O} 2 \mathrm{M}$; $\mathrm{CaSO}_{4} \cdot 2 \mathrm{H}_{2} \mathrm{O} 2,5 \mathrm{M}$; $\mathrm{MgSO}_{4} \cdot 7 \mathrm{H}_{2} \mathrm{O} 2 \mathrm{M}$.

b) Solução $\left(\mathrm{NO}_{3}^{-}\right)=\mathrm{KH}_{2} \mathrm{PO}_{4}+\mathrm{M} ; \mathrm{KNO}_{3} 5 \mathrm{M}$; $\mathrm{Ca}\left(\mathrm{NO}_{3}\right)_{2} \cdot 4 \mathrm{H}_{2} \mathrm{O} 5 \mathrm{M}$; $\mathrm{MgSO}_{4} .7 \mathrm{H}_{2} \mathrm{O} 2 \mathrm{M}$.

c) Solução $\left(\mathrm{NH}_{4}^{+}\right)=\mathrm{KH}_{2} \mathrm{PO}_{4} 1 \mathrm{M} ; \mathrm{K}_{2} \mathrm{SO}_{4} 2 \mathrm{M}$; $\mathrm{CaSO}_{4} \cdot 2 \mathrm{H}_{2} \mathrm{O} \quad 2,5 \mathrm{M}$; $\mathrm{MgSO}_{4} \cdot 7 \mathrm{H}_{2} \mathrm{O} 2 \mathrm{M} ; \quad\left(\mathrm{NH}_{4}\right)_{2} \cdot \mathrm{SO}_{4}=10 \mathrm{M}$.

2) Soluções-estoque para micronutrientes utilizadas na proporção de $1 \mathrm{ml} /$ litro de solução nutritiva para todos os tratamentos:

a) Solução de Fe-EDTA $=$ EDTA $0,07 \mathrm{M}+\mathrm{KOH} 0,3 \mathrm{~N}$ até $\mathrm{pH}$ neutro + $+\mathrm{FeSO}_{4} \cdot 7 \mathrm{H}_{2} \mathrm{O} 0,09 \mathrm{M}$.

b) Solução de micronutrientes $=\mathrm{H}_{3} \mathrm{BO}_{3}: 2,86 \mathrm{~g} / \mathrm{litro} ; \mathrm{MnCl}_{2} \cdot 4 \mathrm{H}_{2} \mathrm{O}: 1,81 \mathrm{~g} /$ litro; $\mathrm{ZnSO}_{4} \cdot 7 \mathrm{H}_{2} \mathrm{O}: 0,22 \mathrm{~g} /$ /itro; $\mathrm{CuSO}_{4} \cdot 5 \mathrm{H}_{2} \mathrm{O}: 0,08 \mathrm{~g}$ /litro; $\mathrm{H}_{2} \mathrm{MoO}_{4} \cdot \mathrm{H}_{2} \mathrm{O}: 0,02$ g/litro. 
Para verificar o efeito das fontes nitrogenadas $\mathrm{NO}_{3}^{-}$e $\mathrm{NH}_{4}^{+}$sobre a atividade do nódulo, as plantas foram cultivadas em solução nutritiva sem $\mathrm{N}$ para permitir uma nodulação completa. Inicialmente, estudou-se o periodo necessário para a manifestação da aplicação do $\mathrm{NO}_{3}^{-}$e $\mathrm{NH}_{4}^{+}$com relação à quantidade de ureideos transportados pela seiva do xilema. Foram realizadas as coletas em plantas com 67 dias, decorridos $0,1,3,5$ e 7 dias do início do tratamento.

Estabelecida a duração do tratamento de plantas noduladas com nitrogênio mineral, efetuou-se o experimento para verificar a ação do tratamento por 7 dias, através dos compostos nitrogenados presentes na seiva do xilema, em plantas noduladas comparadas a plantas-controle $\left(\mathrm{N}_{2}\right)$ e a testemunhas cultivadas com respectivas fontes de nitrogênio, $\mathrm{NO}_{3}^{-}$e $\mathrm{NH}_{4}^{+}$.

A seiva do xilema foi coletada de acordo com McCLURE et al. (1980), das 12 às 15 horas. Como é um método destrutivo, para cada coleta utilizou-se uma planta. O método consistiu no corte do caule imediatamente acima do nó cotiledonar e a coleta do exsudato por capilaridade, encostando-se uma pipeta capilar sobre o vaso do xilema cortado. Meia hora antes do corte do caule, irrigou-se a planta com $500 \mathrm{ml}$ de solução nutritiva. A seiva coletada a cada $0,01 \mathrm{ml}$ pela pipeta foi transferida para um frasco conservado em gelo e posteriormente guardada a $-18^{\circ} \mathrm{C}$. Os aminoácidos foram determinados qualitativa e quantitativamente nas amostras por analisador de aminoácidos pelo método de troca com ligantes (PERKIN-ELMER, 1971) e de aminoácidos livres de YEMM \& COCKING (1955). Os ureídeos, de acordo com TRIJBELS \& VOGELS (1966), ions $\mathrm{NH}_{4}^{+} \mathrm{e}$ $\mathrm{NO}_{3}^{-}$, respectivamente por MCCULLOUGH (1967) e CATALDO et al. (1975).

O delineamenio experimental foi inteiramente casualizado com quatro repetiçóes. Os dados de $\mathrm{NO}_{3}^{-}$e $\mathrm{NH}_{4}^{+}$, ureídeos e aminoácidos totais foram obtidos em cada uma das quatro repetiçōes por tratamento. As análises de ácido alantóico, alantoína e aminoácido, pelo analisador, resultaram da mistura de todas as repetições, em cada dia de coleta, para cada tratamento.

$\mathrm{Na}$ análise dos teores de $\mathrm{NH}_{4}^{+}$do quadro 1, foram considerados os dois tratamentos, $\mathrm{NO}_{3}^{-}$e $\mathrm{NH}_{4}^{+}$, em cinco épocas, uma vez que a relação entre o maior e o menor quadrado médio residual não foi maior que quatro vezes. $O$ teste de Tukey foi aplicado ao nível de $5 \%$.

\section{RESULTADOS E DISCUSSĀO}

Pelo quadro 1, verifica-se que a forma ureídica ácido alantóico predominou sobre a alantoina, com tendência para aumentar a proporção do ácido à medida que as plantas foram supridas com $\mathrm{NO}_{3}^{-}$em relação às supridas com $\mathrm{NH}_{4}^{+}$. 


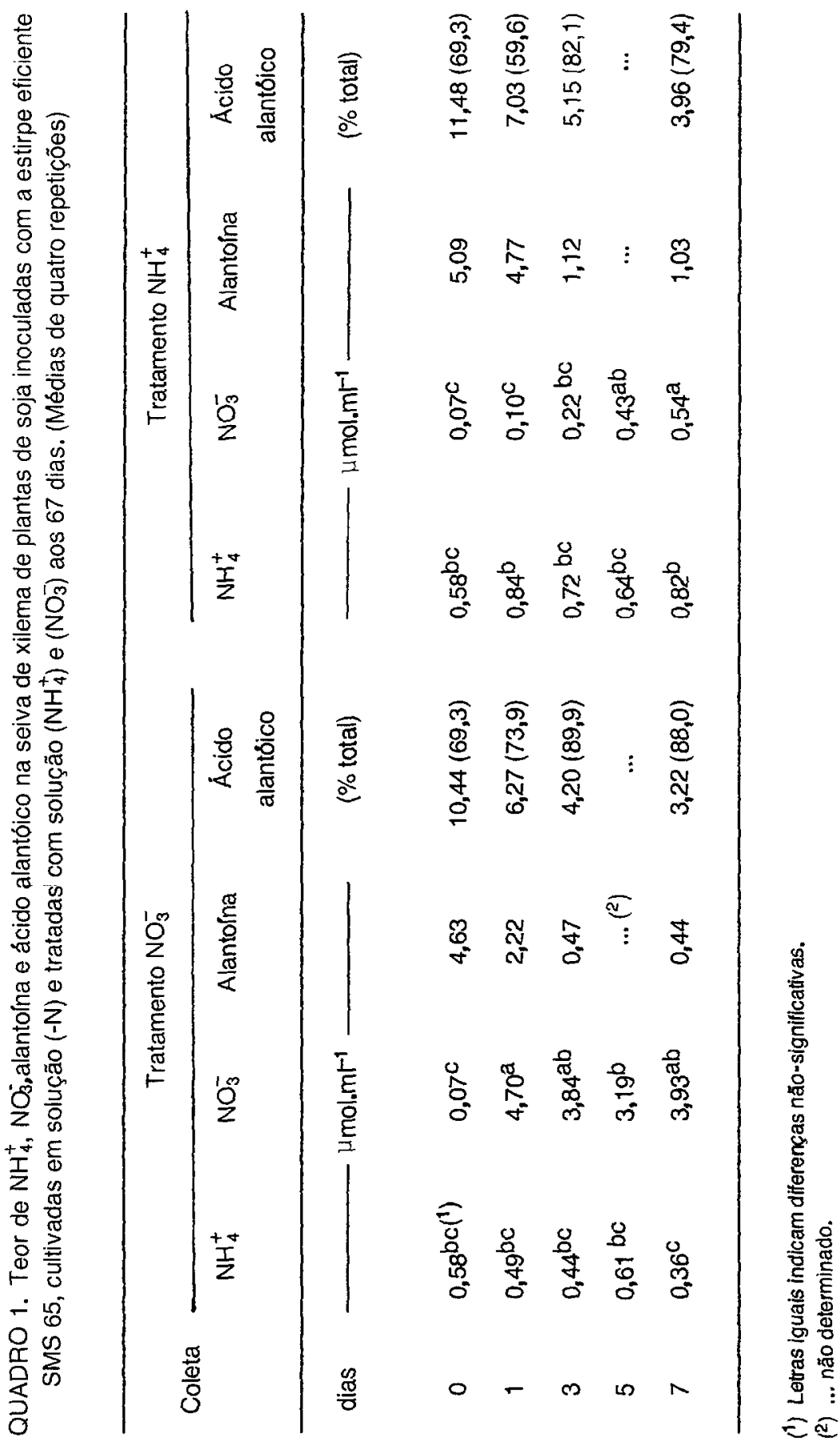


Esses resultados sugerem que a menor quantidade de ureideos na seiva de plantas supridas com ambos, $\mathrm{N}-\mathrm{NO}_{3}^{-}$e N-NH$H_{4}^{+}$, proporcionou condiçōes mais favoráveis para atuação da alantoinase nas raizes, originando altos teores de ácido alantóico. $\mathrm{O}$ teor de nitrato aumentou bastante com a aplicação de $\mathrm{NO}_{3}^{-}$, mas variou pouco com a de $\mathrm{NH}_{4}^{+}$. $\mathrm{O}$ teor de amônia, por outro lado, variou pouco com os dois tratamentos. Esses resultados indicaram a maior transferência de ín $\mathrm{NO}_{3}^{-}$ suprido às raizes, à parte aérea, em relação ao ion $\mathrm{NH}_{4}^{+}$, possivelmente incorporado em aminoácidos nas raízes para não determinar niveis de toxicidade. $O$ ín $\mathrm{NH}_{4}^{+}$é altamente tóxico, tanto para raízes como para folhas (PURITCH \& BARKER, 1967). Sua rápida e eficiente assimilação, portanto, torna-se essencial como mecanismo de desintoxicação (HAYNES \& GOH, 1978). Como a reação da giutamina sintetase incorpora o $\mathrm{NH}_{4}^{+}$em glutamina, é interessante observar, a esse respeito, que a presença da glutamina no xilema, normalmente muito baixa, aumentou significativamente após o tratamento com $\mathrm{NH}_{4}^{+}$(Quadro 3).

O nitrato é tóxico e pode ser acumulado nos vacúolos das raízes. Sua absorção é um processo ativo e parece estar relacionada com a assimilação na forma reduzida. Requer, portanto, mais energia para a incorporação que o $\mathrm{NH}_{4}^{+}$ (absorção por difusão), podendo suceder tanto nas raízes como nos meristemas ou folhas (HAYNES \& $\mathrm{GOH}, 1978$ ).

Para avaliação da proporção de cada composto nitrogenado envolvido no transporte de $\mathrm{N}$ no xilema, os dados foram transformados em porcentagem do $\mathrm{N}$-total (soma dos componentes), levando-se em conta o número de átomos de $\mathrm{N}$ por mol de cada componente (Quadro 2).

QUADRO 2. N-total transportado na forma de ureideos, aminoácidos, $\mathrm{NH}_{4}^{+}$e $\mathrm{NO}_{3}^{-}$na seiva do xilema de plantas de soja (Médias de quatro repetições)

\begin{tabular}{|c|c|c|c|c|c|}
\hline Fonte de $\mathrm{N}$ & Ureideos & Aminoácidos & $\mathrm{NH}_{4}^{+}$ & $\mathrm{NO}_{3}^{-}$ & N-total \\
\hline & & - $\%$ & 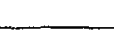 & - - - & umol. $\mathrm{mr}^{-1}$ \\
\hline $\mathrm{N}_{2}$ & 80,2 & 19,0 & 0,7 & 0,1 & 78,89 \\
\hline $\mathrm{NH}_{4}^{+}\left({ }^{1}\right)$ & 36,4 & 61,1 & 1,0 & 1,5 & 54,88 \\
\hline $\mathrm{NO}_{3}^{-}\left({ }^{1}\right)$ & 34,7 & 55,4 & 0,9 & 9,0 & 42,14 \\
\hline $\mathrm{T}-\mathrm{NH}_{4}^{+}\left({ }^{2}\right)$ & 27,7 & 72,3 & $\ldots\left(^{3}\right)$ & ... & 30,20 \\
\hline $\mathrm{T}-\mathrm{NO}_{3}^{-}\left({ }^{2}\right)$ & 26,6 & 60,0 & 1,0 & 12,5 & 32,39 \\
\hline
\end{tabular}

(1) Plantas cultivadas em solução $(-\mathrm{N})\left(\mathrm{N}_{2}\right)$ e tratadas com solução $\left(\mathrm{NH}_{4}^{+}\right)$e $\left(\mathrm{NO}_{3}^{-}\right)$aos 67 dias e cuja coleta foi realizada sete dias após inicio do tratamento.

(2) Plantas $\mathrm{T}-\mathrm{NH}_{4}^{+}$e T-NO $\mathrm{N}_{3}^{-}$foram cultivadas com a respectiva fonte de nitrogênio desde a inoculação.

(3) ... năo determinado. 


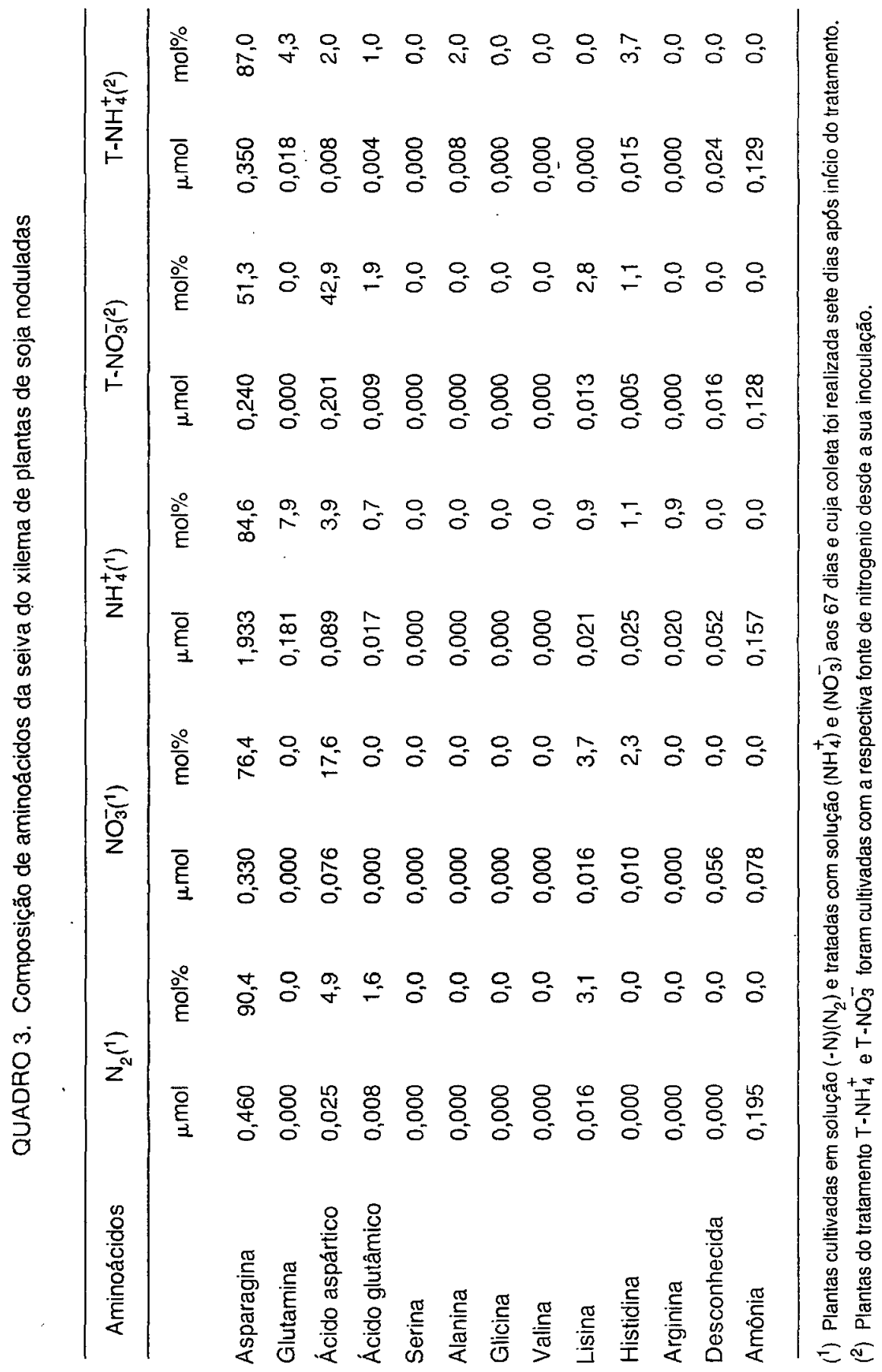


Verificou-se que os ureídeos foram responsáveis por cerca de $80 \%$ do transporte do $\mathrm{N}$ para a parte aérea em plantas dependentes de fixação de $\mathrm{N}_{2}$, com cerca de $20 \%$ na forma de aminoácidos, e apenas traços de $\mathrm{NO}_{3}^{-}$e $\mathrm{NH}_{4}^{+}$. A aplicaçāo de ambos, $\mathrm{N}-\mathrm{NO}_{3}^{-}$e $\mathrm{NH}_{4}^{+}$, diminuiu o $\mathrm{N}$-ureídeo e aumentou o $\mathrm{N}$-aminoácido. No caso do tratamento $\mathrm{NO}_{3}^{-}$, esse aumento na importância dos aminoácidos no transporte de $\mathrm{N}$ decorreu exclusivamente pela queda de ureídeos, de acordo com dados anteriores (SAWAZAKI et al., 1986). Em termos absolutos de nitrogênio, as plantas dependentes de fixação de $\mathrm{N}_{2}$ exportaram maior quantidade de nitrogênio pelo xilema, seguidas pelas plantas supridas com $\mathrm{NH}_{4}^{+}$e depois com $\mathrm{NO}_{3}^{-}$. Esses dados sugerem que o transporte de nitrogênio tenha dependido da interação entre presença de $\mathrm{N}$-mineral no solo e disponibilidade de energia.

Os resultados permitem considerar que parte do $\mathrm{NO}_{3}^{-}$foi assimilado fotossinteticamente na parte aérea (neste experimento cerca de $10 \%$ de $\mathrm{N}^{-\mathrm{NO}_{3}^{-}}$e apenas $1 \%$ de $\mathrm{N}_{-} \mathrm{NH}_{4}^{+}$foram transportados para a parte aérea) e que a absorção do $\mathrm{NH}_{4}^{+}$, embora seja considerada um processo passivo, necessitou de rápida incorporação, sendo, portanto, um processo dispendioso em energia. Assim, há indicaçōes de que a incorporação do $\mathrm{N}_{-} \mathrm{NH}_{4}^{+}$às raizes possa requisitar mais energia do que a incorporaçāo do $\mathrm{N}^{-\mathrm{NO}_{3}^{-}}$. Por outro lado, o processo de fixação de $\mathrm{N}_{2}$ é reportado como mais dispendioso em energia do que a incorporação do $\mathrm{N}_{-} \mathrm{NO}_{3}^{-}$e N-NH$H_{4}^{+}$. Entretanto, foi verificada a dependência do tipo e quantidade de nitrogênio transportado com a energia disponivel: o tipo de composto nitrogenado transportado pelo xilema determinou a quantidade de $\mathrm{N}$-total translocado e dependeu do tipo de $\mathrm{N}$ presente no solo, que, por sua vez, em face do maior ou menor requerimento energético, determinou o composto nitrogenado transportado. Estudos anteriores, ligando a energia disponivel do solo à translocação de composto nitrogenado, originaram a hipótese da inibiçāo da fixação de $\mathrm{N}_{2}$ pela presença de N-mineral: a energia consumida pelos processos assimilatórios de $\mathrm{N}$-mineral pode levar a uma diminuição da disponibilidade de fotossintatos para o processo de fixação de $\mathrm{N}_{2}$ (WONG, 1980; NOEL et al., 1982). STREETER (1985) não encontrou diferenças na composição de carboidratos dos nódulos de plantas com inibição da fixação de $\mathrm{N}_{2}$ pelo nitrato em relação aos de plantas-controle. A fixação de $N_{2}$, processo mais dispendioso de energia, possibilita maior produção de ureídeos, que exportam mais nitrogênio que os aminoácidos. Teoricamente, parece preferivel utilizar o $\mathrm{N}-\mathrm{NH}_{4}^{+}$em relação ao $\mathrm{N}^{-N_{3}^{-}}$como fertilizante nitrogenado iniciat, pois o $\mathrm{NH}_{4}^{+}$possibilita maior transporte de nitrogênio pelo xilema.

Quanto à análise de aminoácidos, verificou-se (Quadro 3) a tendência de o tratamento com $\mathrm{NO}_{3}^{-}$originar baixo teor de asparagina (Asn) e maior de ácido aspártico (Asp) em relação ao com $\mathrm{NH}_{4}^{+}$, que, por sua vez, parece aumentar o teor de glutamina (Gln). Esses dados sugerem que a glutamina e a asparagina seriam maiores na seiva de planta com adiçăo de $\mathrm{NH}_{4}^{+}$do que com $\mathrm{NO}_{3}^{-}$, devido ao maior gasto de energia para a rápida incorporação da amônia pela glutamina sintetase, de modo a não ocorrerem niveis tóxicos. Assim, ocorreria a falta de C 
quando, segundo MIFLIN \& LEA (1977), a asparagina atuaria como estoque temporário de $\mathrm{N}$ reduzido, ocorrendo a diversificação de glutamina para asparagina pela asparagina sintetase, habilitando a planta a prevenir o aparecimento do $\mathrm{NH}_{4}^{+}$ tóxico. Nem toda a glutamina, porém, seria metabolizada em asparagina pela falta de suficiente asparagina sintetase. Já na seiva de plantas tratadas com $\mathrm{NO}_{3}^{-}$, onde menos energia seria gasta para absorção de nitrogênio, ocorreria a inibição da asparagina sintetase, e o aspartato formado via intermediários do ciclo de Krebs (MITCHELL \& BIDWELL, 1970), não sofreria total amidação através da glutamina, via asparagina sintetase (LEA \& MIFLIN, 1980), diminuindo a formação da asparagina.Supõe-se que a adição de fonte externa de $\mathrm{N}$, visto diminuir a fixação, processo altamente dispendioso em energia, aumente a quantidade de carbono nas raízes, favoreça a glutamina sintetase-glutamato sintase e a formação de glutamato e demais aminoácidos. Isso parece confirmado pela maior diversificação de aminoácidos encontrada na seiva de plantas tratadas com $\mathrm{N}$-mineral. As altas porcentagens de asparagina encontradas em todas as plantas confirmaram a via glutamina ligada a asparagina (FUJIHARA \& YAMAGUCHI, 1980), que foi relatada como a preferencial para a assimilação do $\mathrm{NH}_{4}^{+}$por REYNOLDS et al. (1982). Concluiu-se, portanto, que a diferenciaçāo na formação de aminoácidos seria decorrente dos processos específicos de absorção de nitrogênio.

\section{CONCLUSÕES}

1. Os três processos de assimilação de nitrogênio, fixação de $N_{2}$, absorção de $\mathrm{NH}_{4}^{+}$e absorção de $\mathrm{NO}_{3}^{-}$, originaram aminoácidos e ureídeos, sendo a fixação mais voltada para a formação de ureídeos e a absorçāo de $\mathrm{N}$-mineral, para a formação de aminoácidos.

2. Foi encontrada maior proporção de ácido alantóico em relação a alantoina, e essa proporção aumentou com a exposição de planta a $\mathrm{N}$-mineral, sugerindo a ocorrência de maior atividade da alantoinase quanto menor o teor de ureideos.

3. O teor de nitrato no xilema aumentou com a aplicação do $\mathrm{NO}_{3}^{-}$às raízes, mas variou pouco com a aplicação de $\mathrm{NH}_{4}^{+}$, enquanto o teor de amônia alterou-se pouco com ambos os tratamentos. Esses resultados indicam a maior transferência de lón $\mathrm{NO}_{3}^{-}$à parte aérea em relação a lon $\mathrm{NH}_{4}^{+}$.

4. Considerando-se os três processos de assimilação, o transporte de nitrogênio pelo xilema foi maior para o processo de fixação de $N_{2}$, decrescendo para o de absorção de $\mathrm{NH}_{4}^{+}$e para o de absorção de $\mathrm{NO}_{3}^{-}$, sugerindo que o transporte de nitrogênio tenha dependido da interação entre presença de $\mathrm{N}$-mineral no solo e disponibilidade de energia. 
5. Independente do tratamento, a asparagina foi o aminoácido encontrado em maior quantidade no xilema. $\mathrm{O}$ tratamento com $\mathrm{NH}_{4}^{+}$originou seiva de xilema com maior teor de glutamina e asparagina e menor de ácido aspártico, em relação àquele com $\mathrm{NO}_{3}^{-}$.

\section{SUMMARY \\ XYLEM SAP COMPOSITION OF SOYBEAN PLANTS TREATED WITH DIFFERENT NITROGEN SOURCES}

Soybean plants, inoculated with Rhizobium japonicum, were grown in vermiculite with a nitrogen free nutrient solution in a greenhouse, in the Experimental Station of Campinas, Instituto Agronômico, State of São Paulo, Brazil. The effects of $\mathrm{NO}_{3}^{-}$and $\mathrm{NH}_{4}^{+}$were studied in terms of ureide and amino acid levels in the xylem sap. Nodulated plants were treated with nutrient solution either containing $\mathrm{NO}_{3}^{-}(15 \mathrm{mM})$, or $\mathrm{NH}_{4}^{+}(10 \mathrm{mM})$, or without nitrogen (control) for 7 days, near the flowering period. Higher proportion of alantoic acid was found relative to allantoin, and this proportion increased in plants grown on mineral $\mathrm{N}$. The $\mathrm{NH}_{4}^{+}$ion had an intermediary effect compared to the other $\mathrm{N}$-assimilatory processes, with respect to the quantity of $\mathrm{N}$ transported to the aerial parts, suggesting that the mecanism of transport depended on the interaction between the soil mineral nitrogen and the energy available. Asparagin was the amino acid in the greatest quantity in the xylem, independent of the treatment. Ammonium did not alter the levels of $\mathrm{N}-\mathrm{NH}_{4}^{+}$in the sap, but increased slightly the level of $\mathrm{NO}_{3}^{-}$. Nitrate caused slight increase in aspartic acid and large in $\mathrm{NO}_{3}^{-}$content in the sap. These results suggested that the differences in the amino acid synthesis proceeded of a specific pathway of nitrogen uptake.

Index terms: soybean, amino acids, ureides, symbiotic fixation, nitrogen nutrition.

\section{REFERÊNCIAS BIBLIOGRÁFICAS}

ATKINS, C.A.; PATE, J.S.; GRIFFITHS, G.J. \& WHITE, S.T. Economy of carbon and nitrogen in nodulated and non-nodulated $\left(\mathrm{NO}_{3}^{-}\right.$-grown) cowpea (Vigna unguiculata $(\mathrm{L})$. Walp). Plant Physiology, 66:978-983, 1980.

BOLLARD, E.G. Transport in the xylem. Annual Review of Plant Physiology, 11:141-166, 1960.

CATALDO, D.A.; HAROON, M.; SCHADER, L.E. \& YOUNGS, U.L. Rapid colorimetric determination of nitrate in plant tissue by nitration of salicylic acid. Communication in Soil Science and Plant Analisys, 6:71-80, 1975. 
COTTINGHAM, D.G.H. \& JONES, L.C.P. The influence of nitrate supply on nitrogen fixation during growth of the field bean Vicia faba in sand. Physiologia Plantarum, 48:116-120, 1980.

FINKE, R.L.; HARPER, J.E. \& HAGEMAN, R.H. Efficiency of nitrogen assimilation by

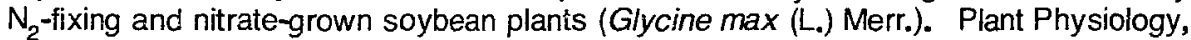
70:1178-1184, 1982.

FUJIHARA, S. \& YAMAGUCHI, M. Asparagine formation in soybean nodules. Plant Physiology, 66:139-151, 1980.

-; YAMAMOTO, K. \& YAMAGUCHI, M. Possible role of allantoin and the influence of nodulation on its production in soybean plants. Plant and Soil, 48:233-242, 1977.

HAYNES, R.J. \& GOH, K.M. Ammonium and nitrate nutrition of plant. Biological Review, 53:465-510, 1978.

HERRIDGE, D.F. Relative abundance of ureides and nitrate in plant tissues of soybean as a quantitative assay of nitrogen fixation. Plant Physiology, 70:1-6, 1982a.

- Use of the ureide technique to describe the nitrogen economy of field-grown soybeans. Plant Physiology, 70:7-11, 1982b.

LEA, P.J. \& MIFLIN, B.J. Transport and metabolism of the asparagine and other nitrogen compounds within the plant. The Biochemistry of Plants, 5:569-607, 1980.

MCCULLOUGH, $\mathrm{H}$. The determination of ammonia in whole blood, by a direct colorimetric method. Nitrogen determination-Berthelot. Clinica Chimica Acta, 17:297-304, 1967.

MCCLURE, P.R.; ISRAEL, D.W. \& VOLK, R.J. Evaluation of the relative ureide content of xylem sap as an indicator of $\mathrm{N}_{2}$ fixation in soybeans. Plant Physiology, 66:720-725, 1980.

MARCUS-WYNER, L. \& RAINS, D.W. Patterns of ammonium absorption and acetylene reduction during soybeans development growth. Plant Physiology, 59:79-82, 1983.

MATSUMOTO, T.; YATAZAWA, M. \& YAMAMOTO, R. Incorporation of ${ }^{15} \mathrm{~N}$ into allantoin in nodulated soybean plants supplied with ${ }^{15} \mathrm{~N}_{2}$. Plant \& Cell Physiology, 18:459-462, 1977.

MIFLIN, B.J. \& LEA, P.J. Amino acid metabolism. Annual Review of Plant Physiology, 28:299-329, 1977.

MITCHELL, D.J. \& BIDWELL, R.C. Comportaments of organic acid in the synthesis of asparagine and homoserine in pea roots. Canadian Journal of Botany, 48:2001-2007, 1970.

NOEL, K.D.; CARNEOL, M. \& BRILL, W.J. Nodule protein synthesis and nitrogenase activity of soybeans exposed to fixed nitrogen. Plant Physiology, 70:1236-1241, 1982.

OHYAMA, T. \& KUMAZAWA, K. Assimilation and transport of nitrogenous compounds originated from ${ }^{15} \mathrm{~N}_{2}$ fixation and ${ }^{15} \mathrm{NO}_{3}^{-}$absorption. Soil Science and Plant Nutrition, 25:9-19, 1979.

PERKIN-ELMER. instruction manual for ligand exchange chromatography, no $6499-$ E. s.l., 1971. 70p.

PURITCH, G.S. \& BARKER, A.V. Siructure and function of tomato leaf chloroplasts during ammonium toxicity. Plant Physiology, 42:1229-1238, 1967.

REYNOLDS, P.H.S.; BOLAND, M.J.; BLEVINS, D.G.; SCHUBERT, K.R. \& RANDALL, D.D. Enzymes of amide and ureide biogenesis in developing soybean nodules. Plant Physiology, 69:1334-1338, 1982. 
SAWAZAKI, H.E.; SODEK, L. \& LOPES, E.S. Efeito de fonte externa de nitrogênio no transporte de compostos nitrogenados em plantas de soja (Glycine max (L.) Merrill) cultivar Santa Rosa. In: REUNIĀO LATINO-AMERICANA SOBRE RHIZOBIUM, 12. Campinas, 1986. Anais. Campinas, Instituto Agronômico, 1986. p.172-179.

SCHUBERT, K.R. Enzymes of purine biosynthesis and catabolism in Glycine max. Comparison of activities with $N_{n}$ fixation and composition of xylem exudate and nodule development. Plant Physiology, 68:1115-1122, 1981.

TRIJBELS, F. \& VOGELS, G.D. Dearadation of allantoin by Pseudomonas acidovorans. Biochemica et Biophysica Acta, 113:292-301, 1966.

WONG, P.P. \& STENBERG, N.E. Effects of directly and indirectly applied nitrate on nodulation and nitrogen fixation (acetylene reduction) activity of soybeans. Plant Physiology, 65(6):108, 1980. Suppl. Abstracts n. 594.

YEM, E.W. \& COCKING, E.C. The determination of aminoacids with ninhydrin. Analyst, 80:209-213, 1955.

ZENGBÉ, M.; TILLARD, P.; CLEYET-MAREL, J.C. \& SALSAC, L. Influence de la souche de Rhyzobium et de l'azote minéral sur la synthèse des uréides chez le soja. Physiologie Vegetale, 22:285-294, 1984. 